\title{
Contra uma esquerda desarticulada e enfraquecida
}

Angícia Gomes Pereira Mourão

BESANCENOT, Olivier; LÖWY, Michael. Afinidades revolucionárias: nossas estrelas vermelhas e negras. Por uma solidariedade entre marxistas e libertários. São Paulo: Editora Unesp, 2016. 196p.

O lançamento do livro Afinidades Revolucionárias, no terraço do prédio da Editora Unesp, em São Paulo, em outubro de 2016, contou com uma plateia lotada para ver a apresentação da obra por um de seus autores, Michael Löwy (NOSSAS..., 2016). Nesse momento, alguns debatedores ressaltaram não só a discussão política empreendida por Löwy e seu parceiro de escrita, Olivier Besancenot, mas também a narração de exemplos de estratégias de ação e de diálogos entre marxistas e anarquistas/libertários, aumentando o poder de resistência contra forças políticas reacionárias. Nesse sentido, o livro se mostra uma leitura particularmente pertinente na atual conjuntura brasileira, marcada por recorrentes golpes, perdas e assaltos aos trabalhadores.

No início do livro, Besancenot e Löwy propõem que historiadores brasileiros se debrucem sobre a história do movimento operário no Brasil, considerando não apenas os conflitos, mas principalmente as convergências entre as correntes anarquistas e marxistas. Essa proposta se embasa em alguns eventos históricos e figuras de intelectuais e militantes que tentaram formular um "marxismo libertário".

Já no prefácio, os autores nos apresentam exemplos brasileiros: o embate da Frente Única Antifascista e partidários da Aliança

\section{Angícia Gomes Pereira Mourão}

Graduada em Letras (UFC) e em Ciências Sociais (UECE). Mestre em Sociologia em Sociologia (PPGS/UECE). Pesquisadora do Observatório das Nacionalidades. E-mail: angicia@gmail.com. 
Integralista Brasileira (AIB), em 1934, na Praça da Sé, em São Paulo. Nessa ocasião, dizem os autores, socialistas, comunistas do PCB, trotskistas, anarquistas, exilados italianos e sindicalistas se uniram contra um inimigo comum: os "camisas verdes" da AIB, inspirados pelo fascismo italiano. Histórias como essa não pertencem apenas ao passado, haja vista as recentes manifestações de rua contrárias ao aumento da tarifa da passagem do transporte público, nas capitais do país, organizadas pelo Movimento Passe Livre, rede federativa e horizontal que se tornou nacionalmente conhecida em 2013.

É disso que Besancenot e Löwy falam na introdução de seu livro: sob o signo da I Internacional, a associação revolucionária entre marxistas e anarquistas deve ser contada, diferenciando-se da historiografia tradicional do movimento operário no Brasil, que confere cores apenas às divergências entre essas correntes. Sem subestimar os conflitos, eles narram "outra vertente da história, não menos importante, mas frequentemente esquecida, algumas vezes mesmo deliberadamente descartada: a das alianças e solidariedade atuantes entre anarquistas e marxistas" (BESANCENOT; LÖWY, 2016, p. 14).

Dessa feita, o objetivo dos autores poderia parecer ser o de traçar o percurso histórico e a definição desse marxismo libertário; no entanto, eles mesmos ressaltam que não é isso que pretendem. Tendo em vista que o marxismo libertário não é uma doutrina, eles propõem uma reflexão provisória sobre o tema, cujo ponto de partida, o marxismo, se deve muito mais às suas trajetórias intelectuais e políticas do que a uma necessidade epistêmica. O conjunto dos capítulos, portanto, apresenta um corpus de uma afinidade revolucionária, que os autores afirmam ser "a vontade comum de desvencilhar-se, pela revolução, da ditadura do capital para construir uma sociedade desalienada, igualitária, liberada do jugo autoritário do Estado." (BESANCENOT; LÖWY, 2016, p. 188).

Dividido em introdução, quatro capítulos de desenvolvimento e conclusão, o conteúdo do livro foi discutido por ambos os autores, mas a sua escrita foi repartida entre eles. No primeiro capítulo, Löwy e Besancenot nos reapresentam a fatos históricos de importância do movimento operário europeu e das lutas 
revolucionárias, como a I Internacional (1864) e a Comuna de Paris (1871), o Primeiro de Maio de 1886, a fundação de um "sindicalismo fora da norma" e autogerido com a Confederação Geral do Trabalho (1895), a Carta de Amiens (1906), a Revolução Espanhola (1936 - 1937) e o Maio de 68 francês.

Tomemos como exemplo a análise que fazem da I Internacional e da Comuna de Paris. Eles afirmam que, desde o começo da I Internacional, as correntes libertárias (em particular, as proudhonianas) estão presentes e, mesmo após tensões, cooperam fraternalmente com as correntes marxistas no momento da Comuna de Paris. A Comuna sem dúvidas foi "um modelo ímpar na história das revoluções sociais" (BESANCENOT; LÖWY, 2016, p. 19), tendo sido organizada democraticamente por meio do sufrágio universal e uma "experiência profundamente pluralista" (BESANCENOT; LÖWY, 2016, p. 19), na medida em que associa seguidores das ideias de Marx, proudhonianos de esquerda, jacobinos, blanquistas e republicanos sociais. Alguns textos redigidos por Marx no calor dos acontecimentos, inclusive, denotam sua forte rejeição à máquina do Estado, retratada como um "aborto sobrenatural da sociedade", uma "jiboia constritora" e um "pesadelo sufocante", dentre outras metáforas (MARX, 2008).

Em conformidade com essa narrativa, eles também discutem acontecimentos mais recentes, como a organização do Fórum Mundial Social, a partir de 2001, o movimento dos Black Blocks, os Indignados na Europa, o Occupy Wall Street nos Estados Unidos e o Movimento Passe Livre no Brasil. Eles classificam esses eventos entre os de caráter altermundialista, em reação ao neoliberalismo no início dos anos 1990, e os inspirados nos Indignados da Espanha, em resistência à grande crise do capitalismo de 2008. Essa mobilização comum de marxistas revolucionários e anarquistas perdurou durante os anos 2000 e, em alguns momentos, se deveu aos primeiros a sua organização; contudo, os autores ressaltam que em muito contribuíram os libertários - como com a desconfiança sadia em relação à burocracia de sindicatos institucionalizados, com uma prática horizontal, oposta ao verticalismo dos partidos de esquerda, ou com novas formas de ação pela ocupação de praças centrais nas cidades em que se deram as manifestações. 
Ainda no primeiro capítulo, os autores apresentam um rol de figuras históricas de militantes que, por vezes, participaram dos eventos de resistência narrados anteriormente. Essas personagens também têm em comum o fato de terem oscilado entre o marxismo e o anarquismo, de acordo com suas reflexões políticas e conjunturas específicas. Elas são Louise Michel (1830 - 1905), Pierre Monatte (1881 - 1960), Rosa Luxemburgo (1870 - 1919), Emma Goldman (1869 - 1940), Buenaventura Durruti (1896 - 1936), Benjamin Péret (1899 - 1959) e o subcomandante Marcos (1957), porta-voz da Revolta Zapatista iniciada em 1994, no México. Como os próprios autores destacam, desde as manifestações do século XIX, as mulheres se juntaram aos homens e conduziram ações e reflexões políticas de envergadura.

Uma ressalva a respeito de uma dessas personagens nos parece pertinente. No decorrer de algumas páginas, eles afirmam que as críticas de Rosa Luxemburgo ao marxismo - em particular, no que se refere ao autoritarismo burocrático do movimento operário, à valorização da espontaneidade das massas e à defesa de um antinacionalismo e de uma revolução proletária "por baixo" - guardam em si uma afinidade latente com o anarquismo. Essa hipótese, no entanto, não é mantida por muito tempo pelos próprios autores que não podem deixar de mencionar que, em inúmeros escritos, Luxemburgo criticou as ideias anarquistas e permaneceu fiel à ideia marxiana de partido como expressão política de classe. Além disso, cabe lembrar que o posicionamento dessa filósofa marxista divergia particularmente em relação às interpretações kautskyanas e leninistas do movimento revolucionário, o que não seria o mesmo que dizer que ela se aproximaria do movimento libertário.

A apresentação de Löwy e Besancenot de figuras históricas importantes para o "marxismo libertário" continua no terceiro capítulo, quando se debruçam sobre as trajetórias de Walter Benjamim (1894 - 1940), André Breton (1896 - 1966) e Daniel Guérin (1904 1988). De acordo com os autores, Benjamin tem claras inclinações anarquistas em seus primeiros escritos, de 1914 a 1921, ao rejeitar radical e categoricamente as instituições burguesas, mas seu documento marxista-libertário mais importante seria um ensaio sobre o surrealismo, datado de 1929. Nesse texto, Benjamin qualifica 
como grandes anarquistas autores à semelhança de Dostoiévski e Rimbaud, já que seus textos assaltam a ordem moral burguesa, e defende "a carga mágica e libertária" (BESANCENOT; LÖWY, 2016, p. 136) do surrealismo. Dizem que um desejo semelhante existe no surrealista André Breton, adepto do marxismo, mas com flertes constantes com a postura libertária, e no historiador de movimentos anarquistas Daniel Guérin.

Anteriormente, no segundo capítulo do livro, Löwy e Besancenot discutem os momentos de colaboração e ruptura entre marxistas e libertários, quando do desenrolar da Revolução Russa de 1917, da tragédia de Kronstadt e as revoltas anarquistas na Ucrânia de 1918, lideradas por Néstor Makhno. A inicial intervenção das massas de sovietes nos acontecimentos assim como os fluxos e os refluxos da história da Revolução marcam um ponto de acordo entre marxistas e libertários. Contudo, "o espinhoso problema da relação entre os partidos e o próprio processo revolucionário" (BESANCENOT; LÖWY, 2016, p. 99) marcam a primeira de muitas divergências entre essas duas correntes de esquerda.

Embora seja comum a interpretação marxista sobre o Estado proposta e analisada por Lênin (1987), Löwy e Besancenot afirmam que um dos pontos de discordância mais notórios entre marxistas e libertários é a leitura feita da tragédia de Kronstadt. Para os bolcheviques, Kronstadt foi um movimento contrarrevolucionário; para os anarquistas, foi uma tentativa de terceira revolução oprimida pela burocracia do Estado comunista, sendo este em si uma contrarrevolução. Os autores, por sua vez, oferecem seu próprio posicionamento: para eles, "o massacre de Kronstadt significou que, no campo dos sovietes, não havia mais lugar para debater livremente o caminho seguido pela Revolução" (BESANCENOT; LÖWY, 2016, p. 121). Apesar desses contenciosos, são esses mesmos eventos somados às trajetórias citadas que demonstram a troca profícua entre as tradições marxistas e anarquistas, ora baseadas nas críticas às instituições (do Estado e da burguesia), ora na defesa do direito à crítica em meio a processos democráticos.

No quarto capítulo da obra, os autores optaram por apresentar algumas questões que consideram caras ao marxismo libertário, 
como o lugar do indivíduo no projeto comunista e nas ideias anarquistas de vida em sociedade, a tomada de poder das mãos do Estado no processo de mudança social, assim como a combinação de uma política em âmbito local e cotidiano com um projeto de destino comum aos povos, dentre outras.

À vista de tudo isso, Besancenot e Löwy lançam mão de uma linguagem acessível e de uma vasta bibliografia, para trilhar de forma não-linear os encontros entre marxistas e libertários. A menção a diversos personagens históricos de primeira e segunda grandeza, além das datas de diferentes acordos, associações, conferências e discussões, poderia nos fazer pensar, em um primeiro momento, que os autores defendem um modelo de história factual. Contudo, sua narração de subsequentes convergências, tensões e dispersões nos faz reconsiderar essa hipótese para dar lugar à percepção de um modelo de história processual, cujas datas são apenas uma referência pontual, que ajudam o leitor - especialmente o leitor iniciante das correntes marxistas e/ ou libertárias - a não se perder no desenrolar dos acontecimentos.

\section{REFERÊNCIAS}

LÊNIN, V. O Estado e a revolução: o que ensina o marxismo sobre o Estado e o papel do proletariado na revolução. São Paulo: HUCITEC, 1987. MARX, K. A guerra civil na França. In: A revolução antes da revolução. v. 2. São Paulo: Expressão Popular, 2008. p. 339 - 437.

NOSSAS estrelas vermelhas e negras. Fundação Rosa Luxemburgo, [online], 25 out. 2016. Disponível em: <http://rosaluxspba.org/nossasestrelas-vermelhas-e-negras/>. Acesso em: 20 set. 2017. 